\title{
Diagnostic accuracy of cyst fluid amphiregulin in pancreatic cysts
}

\author{
May T Tun', Reetesh K Pai ${ }^{2}$, Shirley Kwok ${ }^{2}$, Aiwen Dong ${ }^{1}$, Aparna Gupta', Brendan C Visser ${ }^{3}$, Jeff A Norton ${ }^{3}$, \\ George A Poultsides ${ }^{3}$, Subhas Banerjee ${ }^{1}$, Jacques Van Dam ${ }^{5}$, Ann M Chen ${ }^{1}$, Shai Friedland ${ }^{1}$, Brennan A Scott ${ }^{4}$, \\ Rahul Verma ${ }^{4}$, Anson W Lowe ${ }^{1,6^{*}}$ and Walter G Park
}

\begin{abstract}
Background: Accurate tests to diagnose adenocarcinoma and high-grade dysplasia among mucinous pancreatic cysts are clinically needed. This study evaluated the diagnostic utility of amphiregulin (AREG) as a pancreatic cyst fluid biomarker to differentiate non-mucinous, benign mucinous, and malignant mucinous cysts.

Methods: A single-center retrospective study to evaluate AREG levels in pancreatic cyst fluid by ELISA from 33 patients with a histological gold standard was performed.

Results: Among the cyst fluid samples, the median (IQR) AREG levels for non-mucinous $(n=6)$, benign mucinous $(\mathrm{n}=15)$, and cancerous cysts $(\mathrm{n}=15)$ were $85 \mathrm{pg} / \mathrm{ml}(47-168), 63 \mathrm{pg} / \mathrm{ml}(30-847)$, and $986 \mathrm{pg} / \mathrm{ml}(417-3160)$, respectively. A significant difference between benign mucinous and malignant mucinous cysts was observed $(p=$ 0.025). AREG levels greater than $300 \mathrm{pg} / \mathrm{ml}$ possessed a diagnostic accuracy for cancer or high-grade dysplasia of $78 \%$ (sensitivity $83 \%$, specificity $73 \%$ ).

Conclusion: Cyst fluid AREG levels are significantly higher in cancerous and high-grade dysplastic cysts compared to benign mucinous cysts. Thus AREG exhibits potential clinical utility in the evaluation of pancreatic cysts.
\end{abstract}

\section{Background}

Pancreatic cysts are increasingly recognized from routine use of computed tomography and magnetic resonance imaging with current prevalence estimates of $2 \%$ in the population, rising to approximately $8 \%$ in the elderly [1,2]. Appropriate diagnosis and management of these cysts is clinically important because approximately half may have potential for malignant transformation to pancreatic adenocarcinoma - a cancer associated with an overall 5-year survival rate of 5\% [3,4]. Cysts with malignant potential include mucinous cystic neoplasms (MCN) and intraductal papillary mucinous neoplasms (IPMN).

Various diagnostic tests, including endoscopic ultrasound (EUS), are employed to facilitate diagnosis and management of pancreatic cysts [5,6]. EUS guided aspiration of cyst fluid provides an opportunity to evaluate for tumor markers such as carcinoembryonic antigen

\footnotetext{
* Correspondence: lowe@stanford.edu

'Department of Medicine, Stanford University, Stanford, CA 94305, USA

Full list of author information is available at the end of the article
}

(CEA) that can differentiate mucinous from non-mucinous cysts with reasonable accuracy. CEA cannot, however, accurately differentiate pre-malignant cysts from malignant cysts [7]. Further, cyst fluid cytology also possesses low sensitivity for diagnosing malignancy [8]. Because progression to cancer may be slow and variable among pre-malignant mucinous cysts, a biomarker that identifies cysts with cancer or high-grade dysplasia may have clinical value by identifying which patients may benefit from immediate consideration for surgery [9-12].

In this study, the diagnostic utility of the secreted epidermal growth factor receptor ligand, amphiregulin (AREG), was explored as a cyst fluid biomarker for the presence of malignancy in pancreatic cysts. AREG was chosen based on previous gene expression studies that identified enhanced Anterior Gradient 2 (AGR2) expression in all pancreatic adenocarcinomas [13]. AGR2 stimulates adenocarcinoma cell growth and supports the development of many features associated with malignant transformation $[14,15]$. A recent study demonstrated that $A G R 2$ 's growth promoting properties are achieved
Ciomed Central

(C) 2012 Tun et al; licensee BioMed Central Ltd. This is an Open Access article distributed under the terms of the Creative Commons Attribution License (http://creativecommons.org/licenses/by/2.0), which permits unrestricted use, distribution, and reproduction in any medium, provided the original work is properly cited. 
through its induction of AREG expression in adenocarcinoma cells [16]. As a secreted molecule, we hypothesized that the AREG concentration within the cyst fluid of adenocarcinomas or high-grade dysplastic lesions possesses diagnostic utility in the evaluation of pancreatic cysts.

\section{Methods}

\section{Cyst fluid samples}

With the approval of the Stanford University Human Subjects Institutional Review Board, a pancreatic cyst fluid bio-repository has been maintained since July 2008 . Patients evaluated at Stanford Hospital and Clinics for endoscopic ultrasound or surgery for pancreatic cysts were offered participation in the study. Cyst fluid was collected at the time of endoscopic ultrasound and/or surgery. Patients with a cyst large enough (typically greater than $1 \mathrm{~cm}$ ) to provide cyst fluid beyond what was required for clinical evaluation was immediately placed on ice, aliquoted, and stored at $-80^{\circ} \mathrm{C}$. Clinical evaluation of the cyst fluid primarily involved 500 microliters of fluid for CEA analysis. Testing for amylase was left to the clinical discretion of the gastroenterologist or surgeon. When an intracystic nodule was seen, the nodule underwent fine needle aspiration for tissue diagnosis. All samples were aliquoted and frozen at $-80^{\circ} \mathrm{C}$ within 30 minutes of collection. All samples assayed were subjected to no more than two freeze-thaw cycles, which does not affect the assay's reproducibility.

\section{Diagnosis of pancreatic cysts}

Cyst diagnosis was determined by surgical pathology or cytology. In each of the surgically resected cases, histology slides were independently evaluated by a pathologist (RKP) for the histology type and grade of the neoplasm. All cases of IPMN and MCN were subclassified based on the grade of dysplasia: low-grade, intermediate-grade, and high-grade, using the WHO classification [17]. In this study, the definition of cancer included cystic lesions with high-grade dysplasia. Benign mucinous cysts included MCN or IPMN lesions with low- or intermediate-grade dysplasia.

\section{AREG ELISA}

Researchers (M.T.T., A.W.L.) blinded to the patients' diagnoses conducted the AREG ELISAs. Cyst fluid AREG was determined using a two-antibody sandwich ELISA (DY262, R\&D systems, Minneapolis, MN) according to the manufacturer's instructions. Standard curves were reproducible over a dynamic range of 5$2,000 \mathrm{pg} / \mathrm{ml}$. Briefly, 100 microliter (ul) of sample was required for analysis and added to a 96-well ELISA plate (Fisher Scientific, Pittsburg, PA) that had been precoated with the capture antibody. After incubation with the detection antibody and streptavidin-HRP, the signal was developed by the addition of 3,3',5,5'-tetramethylbenzidine (TMB, Thermo Scientific, Rockford, IL), followed by the addition of a stop solution, and quantified by absorptive spectrophotometry at 450 and $562 \mathrm{~nm}$ on an automatic plate reader (Biotek, Winooski, VT). Assays for each sample were performed on serially diluted aliquots and performed in duplicate. The diluent consisted of $1 \%$ bovine serum albumin in phosphate buffered saline, pH 7.3. Dilutions within the assay's linear range on the standard curve were chosen. Data demonstrating that the ELISA specifically measures the AREG gene product was previously established [16].

\section{Statistical analysis}

Comparisons between mucinous and non-mucinous cysts and benign mucinous and malignant mucinous cysts were performed. Based on a non-normal distribution of AREG levels by cyst type, the non-parametric Kruskal-Wallis test was used to compare AREG levels between the multiple categories of cysts. The Wilcoxon rank-sum test was used for comparison of 2 cyst types. A receiver operator curve was generated to characterize the accuracy of cyst fluid AREG to diagnose malignant mucinous cysts. When a significant difference was observed, a threshold with highest diagnostic accuracy was used to report the sensitivity and specificity of AREG. Statistical analysis was performed using STATA 11.0 (College Station, TX).

\section{Results}

Patients and cyst types

Thirty-three patients with pancreatic cysts were evaluated (Table 1). The mean age was 61 (range 33 - 83)

Table 1 Summary of Patient and Cyst Characteristics

\begin{tabular}{lc}
\hline Total Patients & 33 \\
\hline Median Age, years (range) & $61(33-83)$ \\
\hline Gender: Male/Female & $2.8(2.0-4.4)$ \\
\hline Median Cyst Size, cm (IQR) & 6 \\
\hline Non-Mucinous & \\
\hline SCN $(n=4)$ & 15 \\
\hline Pseudocyst $(n=1)$ & \\
\hline Other $(n=1)$ \\
\hline Benign Mucinous \\
\hline IPMN BD $(n=9)$ \\
\hline IPMN MD $(n=3)$ \\
\hline MCN $(n=3)$ \\
\hline Cancer $($ in situ) \\
\hline High Grade $(n=4)$ \\
\hline Invasive $(n=8)$ \\
\hline
\end{tabular}


and $54 \%$ (18 of 33) were males. The median cyst size was $2.8 \mathrm{~cm}$ (interquartile range [IQR] $2.0-4.4 \mathrm{~cm}$ ). A histological diagnosis was conferred by surgical pathology for 30 samples and by cyst aspiration cytology for 3 samples. Among the 30 surgical pathology samples, there were 5 adenocarcinomas, 4 cysts with high-grade dysplasia (all MD-IPMN), 15 benign mucinous cysts $(\mathrm{MCN}=3$, BD-IPMN $=9$, and MD-IPMN $=3$ ), and 6 non-mucinous cysts $(\mathrm{SCN}=4, \mathrm{PC}=1$, squamous cyst $=1)$. Histological samples conferred only by cytology $(n=3)$ were cysts associated with unresectable adenocarcinoma.

\section{Diagnostic accuracy of AREG}

Scatter plots of cyst AREG levels by cyst type are shown in Figure 1. The median (interquartile range, IQR) cyst AREG levels for non-mucinous cysts, benign mucinous cysts, and cancerous cysts were $85 \mathrm{pg} / \mathrm{ml}$ (47-168), $63 \mathrm{pg} / \mathrm{ml}$ (30-847), and $986 \mathrm{pg} / \mathrm{ml}$ (417-3160), respectively. Table 2 summarizes cyst AREG values by each type of cyst. No significant difference in AREG levels was appreciated between non-mucinous and mucinous cysts. When mucinous cysts were divided between benign and cancerous cysts a significant difference in cyst AREG levels was observed ( $p=0.025)$.

Based on the difference of cyst AREG levels between benign mucinous and mucinous cancers, a receiver operator curve (ROC) was generated to determine an optimal threshold to diagnose mucinous cancers (Figure 2). As a summary measure of diagnostic accuracy, the area under the ROC was 0.76 (95\% CI 0.56-0.95). At an AREG threshold of greater than $300 \mathrm{pg} / \mathrm{ml}$, the diagnostic accuracy for cancer was $78 \%$ with a sensitivity of $83 \%$ and specificity of $73 \%$. With the prevalence of cancer of $32 \%$ in the sample, the positive and negative predictive value was $71 \%$ and $85 \%$, respectively.

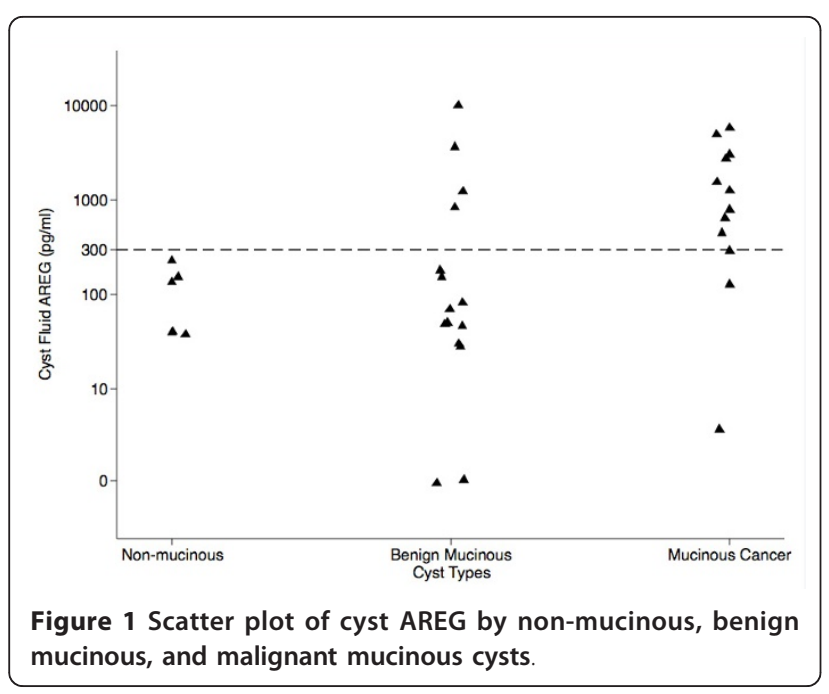

Table 2 Summary of Cyst Fluid AREG performance by Cyst Types

\begin{tabular}{ccc}
\hline Cyst Type $(\mathbf{n}=\mathbf{3 3})$ & Median AREG $(\mathbf{p g} / \mathbf{m l})$ & IQR $(\mathbf{p g} / \mathbf{m l})$ \\
\hline Non-Mucinous $(n=6)$ & 85 & $47-168$ \\
\hline SCN $(n=4)$ & 48 & $44-109$ \\
\hline Pseudocyst $(n=1)$ & 227 & \\
\hline Other $(n=1)$ & 121 & $30-847$ \\
\hline Benign Mucinous $(n=15)$ & 63 & $29-63$ \\
\hline IPMN BD $(n=9)$ & 48 & $71-9041$ \\
\hline IPMN MD $(n=3)$ & 847 & $42-1030$ \\
\hline MCN $(n=3)$ & 202 & $417-3160$ \\
\hline Cancer (in situ) & 986 & $214-546$ \\
\hline High Grade $(n=4)$ & 417 & $986-4367$ \\
\hline Invasive $(n=8)$ & 2047 &
\end{tabular}

Further clinical details on the 12 patients with cancer in this sample are highlighted in Table 3. Four patients had high-grade dysplastic lesions, and included $3 \mathrm{MD}$ IPMN. The majority of patients (10 out of 12) had symptoms (i.e. jaundice, weight loss, abdominal pain) associated with cancer. The majority of patients had imaging evidence of a nodule within the cyst or an associated mass (8 out of 12). Two out of the 12 cases had $A R E G$ levels below $300 \mathrm{pg} / \mathrm{ml}$. One case $(A R E G=125)$ was an intraductal oncocytic papillary neoplasm and the other case $(A R E G=4)$ was a $1.5 \mathrm{~cm}$ cyst adjacent to a pancreatic adenocarcinoma.

\section{Discussion}

A biomarker that can accurately and reliably distinguish cancer or high-grade dysplasia among mucinous pancreatic cystic neoplasms remains an important clinical need. The most accepted cyst fluid biomarker currently is CEA, which is good at differentiating mucinous from

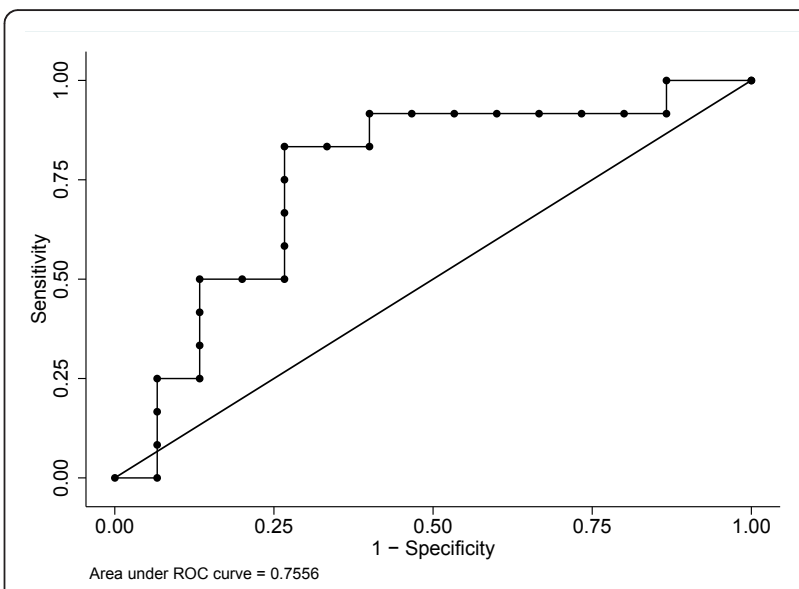

Figure 2 ROC curve analysis of AREG to differentiate benign mucinous from malignant mucinous cysts. 
Table 3 Summary Table of 12 patients with histological diagnosis of Cancer (includes high grade dysplasia)

\begin{tabular}{cccccccc}
\hline $\begin{array}{c}\text { Patient Age/ } \\
\text { Gender }\end{array}$ & Symptomatic & $\begin{array}{c}\text { Cyst Size } \\
(\mathbf{c m})\end{array}$ & Location & $\begin{array}{c}\text { Mural Nodule/ } \\
\text { Mass }\end{array}$ & $\begin{array}{c}\text { AREG level } \\
\text { (pg/ml) }\end{array}$ & $\begin{array}{c}\text { CEA level } \\
\text { (ng/ml) }\end{array}$ & Diagnosis \\
\hline $39 / \mathrm{F}$ & Yes & 2.8 & Tail & Yes & 125 & 15 & $\begin{array}{c}\text { Intraductal Oncocytic Papillary } \\
\text { Neoplasm }\end{array}$ \\
\hline $72 / \mathrm{M}$ & No & 4.6 & Body & No & 303 & 2298 & $\begin{array}{c}\text { Main Duct IPMN with High-Grade } \\
\text { Dysplasia }\end{array}$ \\
\hline $78 / \mathrm{M}$ & Yes & N/A & Diffuse & No & 523 & N/A & $\begin{array}{c}\text { Main Duct IPMN with High-Grade } \\
\text { Dysplasia }\end{array}$ \\
\hline $65 / M$ & Yes & N/A & Diffuse & No & 560 & N/A & Main Duct IPMN with High-Grade \\
Dysplasia
\end{tabular}

non-mucinous cysts. CEA, however, is not reliable for differentiating cancer or high-grade dysplasia among pre-malignant mucinous cysts. As a result, current practice relies on clinical and radiographic data to help clinicians decide which cystic lesions warrant immediate surgery over observation [18]. While helpful, cases of unnecessary surgery or missed opportunities to resect cancer occur [19-21].

AREG's discovery as a potential cyst fluid biomarker arose from observations of increased Anterior Gradient 2 (AGR2) gene expression among pancreatic adenocarcinomas [13]. AGR2 is a highly conserved gene that is associated with mucus secreting cells. AGR2 stimulates adenocarcinoma cell growth and supports the development of many features associated with malignant transformation [14,15]. Closer examination of the gene expression studies showed that AGR2 expression was significantly higher in MCN cysts compared to SCA lesions. Recent studies revealed that $A R E G$, a secreted epidermal growth factor receptor ligand, is specifically induced by AGR2 [16].

In this study, we examined the diagnostic utility of AREG in pancreatic cyst fluid and observed no difference in cyst AREG concentrations between non-mucinous and benign mucinous cysts. Malignant mucinous cysts that included high-grade dysplastic lesions, however, expressed a significantly higher AREG level (median $986 \mathrm{pg} / \mathrm{ml}$ ) compared to benign mucinous cysts (median $63 \mathrm{pg} / \mathrm{ml}$ ) and non-mucinous cysts (median $85 \mathrm{pg} / \mathrm{ml}$ ). By receiver operator curve analysis, an AREG level of $300 \mathrm{pg} / \mathrm{ml}$ provided a diagnostic accuracy for cancer of $78 \%$ (sensitivity $83 \%$, specificity $73 \%$ ). The higher cyst AREG levels observed in malignant cysts is likely a function of the total cellular mass of AREG producing cells. As a benign cyst transitions to a malignant cyst, a hallmark of dysplasia includes a change from simple to stratified epithelium. We hypothesized that this results in a significant increase in the cellular mass of a cyst leading to increased cyst AREG expression. The similarities in cyst AREG levels between non-mucinous and benign mucinous cysts may be related to the physiologic expression of AREG as part of a reparative process in combination with a smaller cellular mass of mucin producing cells. Recent studies have determined that AREG serves an important role in tissue repair after damage in the gastrointestinal tract [22,23].

Because cyst CEA is fairly accurate in differentiating non-mucinous from mucinous cysts, the diagnostic utility of combining both CEA and AREG was considered. There were 21 of the 33 samples where cyst fluid CEA and AREG levels were available for analysis. The median (IQR) CEA levels for the 4 non-mucinous cysts, 11 benign mucinous, and 6 malignant mucinous cysts were $127 \mathrm{ng} / \mathrm{ml}$ (36-844), $1294 \mathrm{ng} / \mathrm{ml}$ (171-8600), and $2400 \mathrm{ng} / \mathrm{ml}$ (1245$11962)$, respectively. Mucinous cysts $(n=17)$ had an elevated CEA (median (IQR) $1311 \mathrm{ng} / \mathrm{ml}$ (277-8600)) compared to non-mucinous cysts $(\mathrm{n}=4)(126 \mathrm{ng} / \mathrm{ml}(36-$ 844) $(p=0.09)$. Although this difference was not statistically significant, this is likely due to the small sample size. Using a cutoff of $192 \mathrm{ng} / \mathrm{ml}$, the sensitivity and specificity of CEA to differentiate non-mucinous from mucinous cysts was $76 \%$ and $75 \%$, respectively- an observation similar to previous reports $[7,24]$. The small size of this sample may also explain why no difference in sensitivity and specificity for cancer was observed when combining AREG and CEA compared to AREG alone. When an AREG 
threshold of $300 \mathrm{pg} / \mathrm{ml}$ was used for the diagnosis of malignant mucinous cysts, the sensitivity was $67 \%$ and the specificity $80 \%$. When AREG was sequentially tested only on pancreatic cysts with a CEA level greater than $192 \mathrm{ng} /$ $\mathrm{ml}$, neither the sensitivity nor specificity changed for cancer.

There are several features of this study that limit the generalizability of these observed results. First, this is a retrospective single tertiary center with a relatively small sample of cyst fluid samples. The small sample size is due in part to restricting the study to surgical patients. Although recruitment was difficult because patients with pancreatic cysts often do not undergo surgery, it was felt that as an initial proof-of-concept study, the use of pathology and surgically resected samples was a necessary gold standard to establish the correct diagnosis. As a result, the impact of a small sample size (in particular the limited cases of non-mucinous cysts) may include inadequate power to demonstrate a difference between non-mucinous and mucinous AREG levels should one truly exist. Second, the 12 cancer cases (including high grade dysplasia) were relatively advanced cases and could likely be identified by current practices without cyst AREG. It is unclear how AREG will perform in cases when imaging and clinical characteristics are non-specific. Many of these limitations, however, can be addressed in the future with prospective, longitudinal validation incorporating a larger sample size and multi-center collaboration.

\section{Conclusions}

The present study represents the translation of recent discoveries in the basic biology of adenocarcinomas to clinical utility in the evaluation of pancreatic cysts. The study reports the discovery of AREG, a secreted epidermal growth factor receptor ligand, as a biomarker with potential diagnostic utility for diagnosing and managing pancreatic cystic neoplasms. Specifically, cyst AREG levels may help accurately identify those cysts with cancer and highgrade dysplastic lesions that require immediate surgical attention. Although not a serum-based test, EUS mediated acquisition of the 100 microliters of fluid necessary for analysis is within current practices for managing pancreatic cysts, and will facilitate validation in future studies.

\footnotetext{
Acknowledgements

The study was supported by National Institutes of Health Award DK063624 (A.W.L.), DK56339 (the Stanford University Digestive Disease Center, A.W.L.), the Stanford Cancer Center, and the Susan \& Edna Riley Charitable Foundation (A.W.L.).
}

\section{Author details}

'Department of Medicine, Stanford University, Stanford, CA 94305, USA. ${ }^{2}$ Department of Pathology, Stanford University, Stanford, CA 94305, USA. ${ }^{3}$ Department of General Surgery, Stanford University, Stanford, CA 94305, USA. ${ }^{4}$ Palo Alto Medical Foundation, Palo Alto, CA 94301, USA. ${ }^{5}$ Department of Medicine, University of Southern California, Los Angeles, CA 90033, USA.
${ }^{6}$ Always Building, Room M211, 300 Pasteur Drive, Stanford, CA 94305-5187, USA.

\section{Authors' contributions}

Study concept and design - MTT, AD, AG, WGP, JVD, and AWL; Acquisition of samples - RKP, SK, BCV, JAN, GAP, SB, JVD, AMC, SF, BAS, RV, and WGP; Analysis and interpretation of data - MTT, RKP, SK, AWL, WGP; Drafting of the manuscript - MTT, AWL, and WGP; Statistical analysis - WGP; Obtained funding - AWL; Co-senior authors and study supervision - AWL and WGP All authors read and approved the final manuscript.

\section{Competing interests}

The authors declare that they have no competing interests.

Received: 2 September 2011 Accepted: 14 February 2012

Published: 14 February 2012

\section{References}

1. de Jong K, Nio CY, Hermans JJ, Dijkgraaf MG, Gouma DJ, van Eijck CH, van Heel E, Klass G, Fockens P, Bruno MJ: High prevalence of pancreatic cysts detected by screening magnetic resonance imaging examinations. Clin Gastroenterol Hepatol 2010, 8(9):806-811.

2. Laffan TA, Horton KM, Klein AP, Berlanstein B, Siegelman SS, Kawamoto S, et al: Prevalence of unsuspected pancreatic cysts on MDCT. AJR Am J Roentgenol 2008, 191(3):802-807.

3. Fernandez-del Castillo C, Targarona J, Thayer SP, Rattner DW, Brugge WR, Warshaw AL: Incidental pancreatic cysts: clinicopathologic characteristics and comparison with symptomatic patients. Arch Surg 2003, 138(4):427-434, discussion 33-4.

4. In SEER Cancer Statistics Review, 1975-2007, National Cancer Institue, Bethesda, MD Edited by: Altekruse S, Kosary CL, Krapcho M, Neyman N, Aminou R, Waldron W, Ruhl J, Howlader N, Tatalovich Z, Cho H, Mariotto A, Eisner MP, Lewis DR, Cronin K, Chen HS, Feuer EJ, Stinchcomb DG, Edwards BK 2010.

5. Brugge WR, Lauwers GY, Sahani D, Fernandez-del Castillo C, Warshaw AL: Cystic neoplasms of the pancreas. N Engl J Med 2004, 351(12):1218-1226.

6. Ahmad NA, Kochman ML, Lewis JD, Ginsberg GG: Can EUS alone differentiate between malignant and benign cystic lesions of the pancreas? Am J Gastroenterol 2001, 96(12):3295-3300.

7. Brugge WR, Lewandrowski K, Lee-Lewandrowski E, Centeno BA, Szydlo T, Regan $S$, et al: Diagnosis of pancreatic cystic neoplasms: a report of the cooperative pancreatic cyst study. Gastroenterology 2004, 126(5):1330-1336.

8. Jacobson BC, Baron TH, Adler DG, Davila RE, Egan J, Hirota WK, et al: ASGE guideline: the role of endoscopy in the diagnosis and the management of cystic lesions and inflammatory fluid collections of the pancreas. Gastrointest Endosc 2005, 61(3):363-370.

9. Das A, Wells CD, Nguyen CC: Incidental cystic neoplasms of pancreas: what is the optimal interval of imaging surveillance? Am J Gastroenterol 2008, 103(7):1657-1662.

10. Rautou PE, Levy P, Vullierme MP, O'Toole D, Couvelard A, Cazals-Hatem D, et al: Morphologic changes in branch duct intraductal papillary mucinous neoplasms of the pancreas: a midterm follow-up study. Clin Gastroenterol Hepatol 2008, 6(7):807-814.

11. Tanno S, Nakano Y, Nishikawa T, Nakamura K, Sasajima J, Minoguchi M, et al: Natural history of branch duct intraductal papillary-mucinous neoplasms of the pancreas without mural nodules: long-term follow-up results. Gut 2008, 57(3):339-343.

12. Kang MJ, Jang JY, Kim SJ, Lee KB, Ryu JK, Kim YT, Yoon YB, Kim SW: Cyst growth rate predicts malignancy in patients with branch duct intraductal papillary mucinous neoplasms. Clin Gastroenterol Hepatol 2011, 9(1):87-93.

13. Lowe AW, Olsen M, Hao Y, Lee SP, Taek Lee K, Chen X, et al: Gene expression patterns in pancreatic tumors, cells and tissues. PLOS One 2007, 2:e323.

14. Wang Z, Hao Y, Lowe AW: The adenocarcinoma-associated antigen, AGR2, promotes tumor growth, cell migration, and cellular transformation. Cancer Res 2008, 68(2):492-497.

15. Ramachandran V, Arumugam T, Wang H, Logsdon CD: Anterior gradient 2 is expressed and secreted during the development of pancreatic cancer and promotes cancer cell survival. Cancer Res 2008, 68(19):7811-7818. 
16. Dong A, Gupta A, Pai RK, Tun M, Lowe AW: The human adenocarcinomaassociated Gene, AGR2, induces expression of amphiregulin through Hippo Pathway Co-activator YAP1 activation. J Biol Chem 2011, 286(20):18301-18310.

17. Cancer TIAfRo: WHO Classification of Tumors of the Digestive System (IARC WHO Classification of Tumors).Edited by: Bosman FT, Carneiro, G Hruban, RH, Theise, ND. World Health Organization; , 4 2010:.

18. Tanaka M, Chari S, Adsay V, Fernandez-del Castillo C, Falconi M, Shimizu M, et al: International consensus guidelines for management of intraductal papillary mucinous neoplasms and mucinous cystic neoplasms of the pancreas. Pancreatology 2006, 6(1-2):17-32.

19. Pelaez-Luna M, Chari ST, Smyrk TC, Takahashi N, Clain JE, Levy MJ, et al: Do consensus indications for resection in branch duct intraductal papillary mucinous neoplasm predict malignancy? A study of 147 patients. Am J Gastroenterol 2007, 102(8):1759-1764.

20. Correa-Gallego C, Ferrone CR, Thayer SP, Wargo JA, Warshaw AL, Fernandez-Del Castillo C: Incidental pancreatic cysts: do we really know what we are watching? Pancreatology 2010, 10(2-3):144-150.

21. Walsh RM, Vogt DP, Henderson JM, Hirose $K$, Mason T, Bencsath $K$, et al: Management of suspected pancreatic cystic neoplasms based on cyst size. Surgery 2008, 144(4):677-684, discussion 84-5.

22. Shao J, Sheng $\mathrm{H}$ : Amphiregulin promotes intestinal epithelial regeneration: roles of intestinal subepithelial myofibroblasts. Endocrinology 2010, 151(8):3728-3737.

23. Berasain C, Garcia-Trevijano ER, Castillo J, Erroba E, Lee DC, Prieto J, et al: Amphiregulin: an early trigger of liver regeneration in mice. Gastroenterology 2005, 128(2):424-432.

24. Park WG, Mascarenhas R, Palaez-Luna M, Smyrk TC, O'Kane D, Clain JE, et al: Diagnostic performance of cyst fluid carcinoembryonic antigen and amylase in histologically confirmed pancreatic cysts. Pancreas 2011, 40(1):42-45.

\section{Pre-publication history}

The pre-publication history for this paper can be accessed here: http://www.biomedcentral.com/1471-230X/12/15/prepub

\section{doi:10.1186/1471-230X-12-15}

Cite this article as: Tun et al:: Diagnostic accuracy of cyst fluid amphiregulin in pancreatic cysts. BMC Gastroenterology 2012 12:15.

\section{Submit your next manuscript to BioMed Central and take full advantage of:}

- Convenient online submission

- Thorough peer review

- No space constraints or color figure charges

- Immediate publication on acceptance

- Inclusion in PubMed, CAS, Scopus and Google Scholar

- Research which is freely available for redistribution

Submit your manuscript at www.biomedcentral.com/submit 